\begin{tabular}{|l|l|}
\hline & \\
PUCRS & HUMANIDADES \\
\hline http://dx.doi.org/10.15448/2178-3748.2020.2.37870 & $\begin{array}{l}\text { Oficina do historiador, Porto Alegre, v. 13, n. 2, p. 1-9, jul.-dez. } 2020 \\
\text { e-ISSN: 2178-3748 }\end{array}$ \\
\hline
\end{tabular}

SEÇÃO: ARTIGOS

\title{
Ensaio sobre as posturas municipais na cidade de Goyaz: 1831-1855
}

Essay on the municipal postures in the city of Goyaz: 1831-1855

\section{Naelma Mendes do \\ Nascimento ${ }^{1}$ \\ orcid.org/0000-0002-4210-0830 \\ naelmamendes@hotmail.com}

Recebido em: 29/4/2020.

Aprovado em: $5 / 8 / 2020$

Publicado em: 21/12/2020.
Resumo: A partir da terceira década do século XIX, autoridades da Província de Goiás (médicos, engenheiros, sanitaristas e politicos), preocupadas com a higiene da cidade, providenciaram decretos, leis e projetos para que fosse resolvida a questão no espaço público. A adoção e a imposição das práticas higiênicas foram analisadas, segundo Moraes (1995), como uma ação dominadora dos grupos no poder. Assim, direcionaram mais atenção para hábitos e costumes, que refletiam na saúde dos populares, contribuindo para a mudança no cenário social e para que epidemias não se dispersassem entre o povo. O objetivo deste artigo é analisar a imposição e a fiscalização de um conjunto de leis responsáveis por regulamentar e disciplinar a postura das pessoas no cotidiano da cidade de Goyaz, na segunda metade do século XIX, em especial, uma resolução com data de 14 novembro de 1856, que atribuía exigências determinando as condições e o manejo para a comercialização de carnes nas ruas públicas da cidade.

Palavras-chave: Código de Posturas. Comércio. Higiene.

Abstract: From the third decade of the nineteenth century, authorities in the Province of Goyaz (doctors, engineers, sanitarians and politicians) were concerned with the hygiene of the city. They provided decrees, laws and projects to solve the matters of public space. The adoption and imposition of hygienic practices were analyzed, according to Moraes (1995), as a dominating action of the groups in power. Therefore, they directed more attention to habits and behaviors, which reflected on people's health, contributed to the change of the social scene and avoided epidemics to disperse among people. The objective of this article is to analyze the imposition and inspection of a set of laws responsible for regulating and disciplining the posture of people in the daily routine of the city of Goyaz, in the second half of the 19th century. The focus will be especially in a resolution dated November 14 1856, which assigned requirements determining the conditions and management for the marketing of meats on the public streets of the city. Keywords: Posture code. Trade. Hygiene.

\section{Introdução}

A questão sanitária, a partir de 1830, despertou a preocupação das autoridades políticas e administrativas da Província de Goiás. Médicos, engenheiros, sanitaristas e políticos providenciaram medidas que poderiam mudar o cenário urbano de Goiás. O discurso médico e sanitarista adquiria, a partir daquele momento, corpo e voz através de decretos e leis (RABELO, 2002). Nesse sentido, é relevante destacar a importância do estudo acerca de temas relacionados à saúde e à higiene em Goiás no periodo em que tais práticas de higiene começam a ter corpo na província. Tais medidas afetaram o consumo e a venda de carne, e foram 
relacionadas à saúde pública. Tais regulamentos indicavam que o não cumprimento da legislação, poderia criar problemas para a cidade. Assim, objetivo deste artigo é analisar a importância dos regulamentos acerca da venda de carne na antiga capital de Goiás, na segunda metade do século XIX. Para tanto, faremos uso dos regulamentos e das posturas municipais.

O espaço público, em parte, era carente de organização e necessitava que o Estado introduzisse práticas sanitárias visando a novos hábitos que atingissem resultados positivos. Para isso, práticas normativas e disciplinares foram utilizadas para esvaziar o espaço público de "elementos perturbadores da ordem e da moral" (RABELLO, 2002, p. 62). Esses eram pessoas de classe inferiores: libertos, forros, negros, prostitutas, bêbados e outros. A propósito, a intenção era ordenar para que o espaço público não ficasse ocupado de pessoas não produtivas (RABELLO, 2002). Moraes (1995, p. 76-77) afirma que não bastava esvaziar as praças e as ruas dos considerados pelo discurso normatizante vadios, vagabundos, doentes e mendigos. Mas, seria necessário discipliná-los para assumirem posturas mais adequadas ao trabalho, e hábitos higienizadores.

Segundo Corbin, as práticas sanitárias começaram a ser desenvolvidas na Europa no final do século XVIII. Eram amparadas nos saberes médicos e científicos. Voltadas principalmente para o espaço público, seu objetivo era que as pessoas adquirissem novos hábitos no cotidiano. Assim, para Corbin (1987, p. 120) a higiene é:

A política sanitária que então se estrutura inspira-se num passado já distante [...] ela assume práticas da ciência antiga, ressurgidas nos campos de regulamento urbano por volta do século XIV. No entanto esse higienismo não se restringe a utilização (do dejeto): a evolução das convicções médicas e mais ainda, os progressos da química já se asseguraram sua modernidade. A estratégia sanitária que se modula então não mais se reveste com caráter episódico daquela desenvolvida quando grassavam epidemias, ela pretende chegar à permanência.

Para o autor, a higiene seria uma prática amparada na ciência. Diferente de outras épocas, a partir daquele momento, objetivava-se que deveria ser uma atividade constante. Ao tornar-se parte do cotidiano das pessoas, e praticada não somente no auge de alguma doença, poderia apresentar efeitos positivos. Em um periodo que a ciência começava a ganhar espaço, defendiam que as doenças eram adquiridas pelo ar, através de odores venenosos e que esses seriam movidos pelo ar até a pessoa. A teoria do miasma, (um princípio que afirmava que as doenças teriam origem nos odores fétidos da matéria orgânica em putrefação) apresentou por um longo período explicações de como acontecia essa aquisição de enfermidades.

Até o final do XIX, no campo da medicina, dominava a teoria miasmática, principio segundo o qual surtos epidêmicos de doenças infecciosas seriam causados pelo ambiente. As condições sanitárias geravam um estado atmosférico, que vinha causar a doença (ROSEN, 1994, p. 211).

Segundo Rosen, acreditava-se que, como resultado de uma sociedade que pouco sabia sobre higiene, e os que sabiam não aplicavam as medidas, o odor das coisas e dos lugares seria o principal propagador das doenças, portanto, era necessário e importante cuidar do ambiente para que o ar fosse livre de impurezas.

\section{A Câmara Municipal 1827-1831}

Segundo Rabelo (2002), em 7 de fevereiro de 1831, foram criadas as primeiras posturas da cidade de Goiás, e inicialmente foram chamadas de posturas policiais, a fiscalização feita pelos policiais era caracterizada pelo rigor. Posteriormente, passaram a ser chamadas de posturas municipais, podendo ser entendidas como um conjunto de ordens, normas e leis que disciplinaram e normatizaram o espaço urbano. Essas, estabeleciam o bom funcionamento da cidade, definindo como cada coisa deveria funcionar e as punições que seriam aplicadas àqueles que descumpriam o decreto imposto.

Conforme Rabelo, as Câmaras Municipais responsáveis pela administração e pela fiscalização de cada cidade, filhas da administração portuguesa, herdaram do período colonial responsabilidades que ajudavam na administração das cidades. Em 1 de outubro de 1828, o Império cria um regimento 
para as Câmaras, em que lhes são retiradas a total responsabilidade que antes possuíam, e acrescidas tantas outras, como tornar-se responsável pela saúde pública. Como observou Rabelo

A lei regulamentar ou regimento das Câmaras Municipais em 1 de outubro de 1828 retira das Câmaras muitas de suas atribuições consolidadas desde o início do período colonial. Assim, as leis e deliberações das câmaras foram elaboradas de acordo com a constituição de 1824, os decretos e leis imperiais, o Código Criminal de 1830, o Código do Processo Civil de 1832, o Regimento de 31 de janeiro entre outros (RABELO, 1997, p. 70)

Ainda segundo Rabelo, através desse novo regimento, as leis da Câmara Municipal, elaboradas em séculos anteriores, foram refeitas. Agora não mais de uma forma generalizada, mas sim por códigos especificos, com o propósito de melhorar a administração local. Segundo Schmachtenberg, a Câmara era a responsável pelo controle dos impostos, concessão de alvarás (licença para funcionamento de estabelecimentos), imposição das posturas e outros. Vale ressaltar que as posturas possuiam um valor jurídico e a organização da sociedade era o seu principal objetivo (SCHMACHTENBERG, 2008, p. 6).

Ao se tornarem posturas municipais passaram a ter fiscais, e não mais policiais, como responsáveis pela fiscalização dos códigos. Os fiscais eram nomeados pelos vereadores, e realizavam visitas, que eram agendadas. Em Corumbá, Mato Grosso, em meados de 1870-1888, essas visitas aconteciam por volta de duas vezes ao ano nos estabelecimentos. Nos açougues, elas sucediam no mínimo uma vez por semana. Toda novidade encontrada durante as visitas era encaminhada aos vereadores e ao presidente da câmara, que logo decidiam a melhor forma de resolver cada caso (NOGUEIRA; SILVA, 2013, p. 147).

Em Goiás as visitas aconteciam diariamente, assim indica o documento a seguir. Comparada à vila de Corumbá, podemos afirmar que a capital da província goiana era mais fiscalizada pelas autoridades, pois estabelecimentos como açougues, eram visitados diariamente. Diferentemente da vila mato-grossense, que não vistoriava todos os dias seus açougues, mas, no mínimo, uma vez por semana. Observe o que diz o documento, sobre o artigo 14 da Postura de fevereiro de 1831,

Publiquei como lei. Palácio do governo da provincia de Goyaz 14 de novembro de 1856

Antonio Augusto Pereira da Cunha

$N^{\circ} 13$.

Assembleia Legislativa Provincial de Goyaz sob proposta da Camara Municipal desta Cidade

Resolve.

Artigo 1: O art 14 das posturas de 7 de fevereiro de 1831 será subentendido e execultado pela maneira seguinte.

$\S 1^{\circ}$. Os marchantes que tiverem talhos em ruas publicas trarão somente para eles a carne que houver de ser vendida diariamente. O resto della, couros e miudezas só poderão ter em outras casas de ruas menos publicas, designadas pelo fiscal, e a comando dos mesmos marchantes.

$\S 2^{\circ}$. Todos os dias serão lavados os utensis do talho, especialmente o cêpo em que se corta a carne; a casa do talho será varrida e limpa diariamente, e as immundícias lançadas fora em lugar designado pelo fiscal.

$\S 3^{\circ}$. Não serão expostos nas ruas públicas couros a secar, e nem outros quaisquer objetos, que infecionem o ar.

A infração do disposto nos § supra-sera punida com oito dias de prisão, ou oito mil reis de multa, e o dobro nas reincidências.

Art $2^{\circ}$. O fiscal visitará diariamente os talhos, promoverá a sua limpeza; poderá entrar, nos termos da lei; no interior das casas onde houver talho, para verificar se lhe cumprido o disposto nas presentes posturas, e no caso de falta de cumprimento deste, será punido com multa de dois mil reis.

Art $3^{\circ}$. Fica o revogados a disposição em contrarias.

Paço da Assembleia Legislativa Provincial de Goyaz 10 de Novembro de 1856.

O Presidente (ilegivel) Antonio (ilegivel)

1. Secretario Antonio José de (ilegivel)

2.Secretário Olavo de Andrade Silva. ${ }^{2}$

A Assembleia Legislativa da Província exigia que o artigo 14 das posturas de 7 de fevereiro 
de 1831 fosse executado no ano de 1856. O artigo, objeto de estudo desse trabalho, em suma estabelecia como deveria ser realizada a venda de carne. Determinava como seriam procedidas as visitas, quais as condições de adequação que deveriam ser encontradas nas casas de talhos, a higiene dos utensilios e o destino do lixo gerado no local. Era observada a qualidade do produto, a limpeza do estabelecimento e quais partes do animal deveriam ser vendidas na casa.

Em casas de ruas públicas, era vendida apenas a carne, o resto era comercializado em outro talho, localizado em uma rua menos pública designada pelo fiscal. A carne deveria ser de um animal abatido recentemente, ela era conhecida como carne verde. 0 3. ${ }^{\circ}$ parágrafo do artigo $14^{3}$ informa que não podiam ser postos para secar nas ruas públicas couro ou quaisquer objetos que infectassem o ar. Acreditavam que o odor emanado dessas e de outras matérias orgânicas poderiam carregar o ar de bactérias e ter como resultado as doenças.

O documento não fala se a carne poderia ser posta a secar no estabelecimento, conclui-se que não, por que é uma matéria orgânica, poderia infeccionar o ar, assim estabelecia o parágrafo 3 das posturas. Da mesma forma, o artigo 14 não comunica a venda da carne seca. Nas ruas menos públicas eram vendidas carnes e miudezas, partes como: pé, cabeça e vísceras. Algo importante de observar é uma "divisão" de carne nas ruas mais e menos públicas, nota-se que as miudezas não eram vendidas no mesmo local de corte de carne.

A imagem a seguir representa um "açougue", uma casa para venda de carne. O estabelecimento era situado no Rio de Janeiro, capital do Brasil. A carne que estava à venda era a carne de porco, facilmente identificada pela cabeça do animal presente na imagem. Na Imagem 1, temos o dono da casa de talho, vestindo uma roupa de um tecido de chita, uma criança e uma mulher, vestidos, mas descalços, indicando que ambos eram escravos e estariam comprando o item que iria compor parte de uma refeição. Do outro lado do balcão, outro homem, funcionário da loja, sem camisa, cortando um pedaço de carne. O estabelecimento não apresenta nenhuma higiene. A imagem é de 1827. nesse período o Império ainda não havia criado o regimento das Câmaras, e a Câmara ainda não havia se tornado responsável pela saúde pública, sequer na antiga capital do Brasil.

Imagem 1 - Loja de carne de porco - J.B Debret, 1827

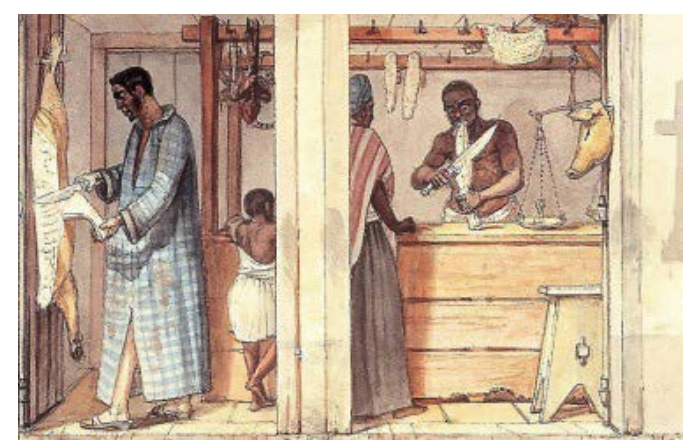

Fonte: Reprodução de imagem do site Ensinar História - Joelza Ester Domingues. ${ }^{4}$

Nota-se na composição da cena da loja de carne suina, a presença de alguns utensilios utilizados no corte e na venda de carne, duas facas, uma balança, os suportes para suspender as peças de carne, além da bancada, que não era um utensílio, mas tinha sua importância pois servia como apoio para cortar a carne e deveria estar sempre limpa. Próximo à cabeça do animal está a balança. Na vila de Corumbá, 1870-1888, o poder público fiscalizava o utensilio usado para pesar a carne. Nogueira e Sena (2013, p. 146) afirmam que essas balanças eram observadas pelas autoridades, que aferiam todos os seus pesos e medidas em um ciclo de 30 dias. Tal medida foi adotada para evitar possiveis fraudes no peso da carne. Ainda sobre a Imagem 1, no lado oposto à balança, o dono do estabelecimento corta o animal, utilizando como suporte para suspender o suíno algo preso à porta do açougue. Na parte superior da ilustração estão outras partes do animal, o toucinho e as vísceras. O trabalhador não demostra nenhum cuidado com a higiene, usando a boca para apoiar a carne e estando sem roupa para cobrir o tronco e os 
membros superiores do seu corpo. Em suma, nessa situação, as portas logo ficariam sujas de matéria orgânica do animal (sangue e sebo), de tal modo que insetos, como moscas, eram facilmente atraídos ao local. Conclui-se que no local também há ratos. Na parte inferior do balcão percebe-se a presença de alguns buracos, certamente feitos por roedores que, durante a noite, se alimentavam de restos do porco.

\section{0 perigo vai além do mau cheiro}

A localização de alguns estabelecimentos envolvia muitos debates. Acreditava-se que o odor das coisas e dos lugares seria o principal propagador das doenças, portanto era necessário cuidar do ar, pois as doenças poderiam por ele ser contraídas. Diante disso, locais destinados ao abate de animais, comércio, cemitérios e outros foram construídos - o primeiro e o último em áreas mais afastadas do meio urbano. Os perigos do mau cheiro, a partir do século XIX, tinham como base uma nova relação entre o homem e o seu meio social (CORBIN, 1987). Muito se discutiu sobre o que poderia ser feito e praticado para que houvesse uma mudança no cenário higiênico da cidade.

O matadouro público da cidade de Goiás, construido até 1881,5 edificado para o abate de animais, era localizado em uma área mais afastada, o odor da matéria orgânica da rês, o sangue, as fezes e o couro no local poderiam contaminar o ar. Em 1828, período que o Império do Brasil elabora uma coleção de leis, ficou estabelecido que, "matadouros tem que ser distante das povoações. O sangue do gado sobre a terra exposto a putrefação". ${ }^{\circ}$ Ele havia sido construido para solucionar questões referentes à saúde e à higiene. Outro destaque para a construção do matadouro, apresentado na cidade de São Paulo em 1848, "é a urgência de a cidade ficar livre dos miasmas. Pois na época eram adotadas medidas de limpezas das ruas e moradias, mas de nada adiantava limpar se estivessem próximas à cemitérios, hospitais, matadouros e depósitos de lixo" (GIORDANO, 2006, p. 79).

Em Corumbá o controle feito pelo estado não conseguiu acabar totalmente com práticas antigas, como o abate em local impróprio e a venda de carne animais doentes. Segundo Nogueira e Sena

Enquanto as autoridades de Corumbá estavam preocupadas com a disciplinarização e "modernização" do espaço urbano mais dinâmico do sul da província de Mato Grosso no final do século XIX, por outro lado, alguns açougueiros burlavam as imposições e procuravam minimizar as despesas e maximizar os lucros, e para isso evitavam o desperdicio do produto que. por sinal, é altamente perecivel (2013, p. 150).

Tais atitudes, citadas no documento, praticadas por açougueiros, eram preocupantes, poderiam indicar que algumas casas de talho estavam apresentando perigo para a população. Na cidade de Goiás, o periódico O Tocantins, por meio de uma publicação em 22 de dezembro de 1855 . chamava atenção das autoridades locais que fiscalizassem não somente as casas de talho, mas todos os locais que vendesse alimento. O jornal publicava, que circulava na cidade um boato, não sabiam se era verídico, que uma casa de talho da capital da província, no dia 21 de dezembro de 1855, estava vendendo carne um animal que morrera porque havia sido picado por cobra, logo ele não poderia ser consumido. Algumas pessoas assustadas com tal situação jogaram fora a tal carne comprada nesse estabelecimento.7 O caso da vila de Corumbá e da cidade de Goiás chama atenção para um aspecto importante, o animal abatido para o consumo, não em todos os casos, não era examinado, podendo está enfermo ou ter sido morto por algo suspeito e, mesmo assim, abatido. Tais atitudes além de serem contrárias ao que definia a legislação, objetivavam o lucro.

\footnotetext{
5 GOIÁS (Estado). Assembéia Legislativa Provincial de Goyaz. Relatório do Presidente da Província de Goyaz, Dr Antonio Gomes Pereira Junior, apresentado à Assembleia Legislativa Provincial de Goyaz, passando a administração da provincia para o Dr Theodoro Rodrigues de Moraes, no dia 22 de fevereiro de 1883. Goyaz Typographia Provincial. 1883. p. 13-14; Instituto de Pesquisas e Estudos do Brasil Central. Doravante IPEHBC, caixa Legislação - Goiás.

6 Coleção das Leis do Império do Brasil, 1828, Lei de 1 de outubro de 1828. Rio de Janeiro. Typographia Nacional 1878.

7 Denúncia feita a um estabelecimento que vendia carne. O Tocantins. Jornal Noticioso. Cidade de Goyaz, ano 1855, n. 58, 22 de dezembro de 1855. Typographia goyazense, p. 6. IPEHBC
} 


\section{0 consumo da carne}

O aumento do consumo de carne verde pode ser explicado pelo aumento da população. Logo que o crescimento populacional aumentou a procura por carne, o resultado foi a multiplicação de pedidos de alvarás, a licença para funcionamento de casas de talho e, em alguns casos, de currais para o abate de animal. Os populares enviavam à Câmara oficios solicitando a solução para a escassez da carne verde. Uma situação semelhante é descrita no documento abaixo:

\section{Ll. ${ }^{\circ}$ e Exm. ${ }^{\circ} \mathrm{Sr}$}

Secretaria da Policia de Goyaz 9 de Outubro de 1855

Ordenando-me V. Exa hoje verbalmente que tomasse alguma providência, que fizesse cessar a grande falta de carne verde, que presentemente se sofre essa cidade, não encontrando nas leis, e posturas em vigor disposição alguma, de que possa lançar mão para obter com eficácia o fim indicado, mandei chamar a minha presença o único individuo, que presentemente vende carne verde e procurei pessuadi-lo a que abastece-se a cidade de maneira que não se sofra a falta de carne, o que ele prometeo-me fazer.

Entretanto offereço a consideração de V. Exa que me ocorre a tall respeito; e vem a ser: solicitar-se da assembleia legislativa provincial com urgência uma resolução autorisando ao governo, ou a pessoa, que este julgar conveniente encarregar, a contratar com qualquer pessoa, que se obrigue sob certa multa a matar diariamente um certo numero de rezes, e a vender por preço, que não exceda a um máximo que se fixar, ficando em compensação direito provincial estabelecido sobre esse gênero de commercio, elevando-se ao mesmo tempo convenientemente os mesmos direitos relativamente a qualquer outros individuos, que quiserem vender carne verde, ou secca.

Deos guarde a ${\underline{V} . x_{x}}^{a}-l l m^{\circ}$ e Exm ${ }^{\circ}$ Sr. dr. Antonio Pereira da Cunha, presidente da provincia

Com urgência a comissão de constituição e poderes.

Dada a hora marca-se para ordem do dia: $1 .^{a}$ a discussão dos projectos n. ${ }^{\circ} 6$ e $7,2^{a}$, do de n. ${ }^{\circ}$ 1, e continuação das posturas da câmara municipal de S. Domingos (do art. 13 em diante)

Levanta-se a sessão as 3 horas da tarde. ${ }^{8}$

Publicado no jornal O Tocantins, um habitante não identificado residente na cidade de São Domingos envia à Secretaria de Polícia de Goyaz, em
1855, um oficio solicitando que as autoridades da provincia de Goyaz resolvessem a situação descrita, a falta de abastecimento de carne verde. 0 habitante pedia que fosse estipulada uma quantidade exata de animais abatidos diariamente, e que o preço fixado não fosse ultrapassado. O autor do oficio alerta uma pequena falha. Segundo ele, as posturas de São Domingos não apresentavam nenhuma solução quando houvesse a falta do alimento, por isso ele enviava o pedido à Secretaria de Polícia. Segundo Moraes, "qualquer pessoa do povo teria direito de requerer o cumprimento das posturas, desde que possuissem endereço fixo e um trabalho" (1995, p.131). As posturas criadas em 1831, com o passar do tempo e o surgimento de determinadas situações, foram modificadas através de resoluções, decretos que a Assembleia Legislativa sancionava (RABELO, 2002, p. 17).

Outro dado importante apresentado no documento enviado à Secretaria de Polícia de Goyaz é que ainda não havia uma frequência no abate de gado, acontecia apenas algumas vezes por semana. A carne verde não poderia ser estocada por ser um alimento que deve ser consumido logo depois de comprado. O oficio requeria que fosse estipulada uma quantidade exata de abate diário para que a população não sofresse com a falta da carne verde e que o preço da carne não excedesse ao que fosse fixado. As mesmas condições solicitadas nesse oficio também seriam aplicadas àqueles que vendiam carne seca.

A ausência do corte verde poderia aumentar o consumo da carne seca, um tipo mais salgado e que era não abatida no mesmo dia, podia ser consumida alguns dias depois de comprada (NOGUEIRA; SENA, 2013). Poderia torna-se carne seca a carne verde que não fosse vendida na casa de talho e consumida no mesmo dia que foi colocada à venda. Dito isso, ela poderia ser posta no sol para secar, ficaria conservada; o processo duraria alguns dias.

Em 1855, Luis Esteves Rodrigues, habitante da cidade de Goyaz, requisitou à Câmara Municipal uma licença para a abertura de um corte de carne verde e a construção de um curral.

\footnotetext{
8 Ofício enviado a Secrataria de Polícia de Goyaz. O Tocantins. Jornal Noticioso. São Domingos, ano 1855, n. 58, p. 3. Typographia goyazense, 9 de outubro de 1855. IPEHBC
} 
Diz Luis Esteves Rodrigues, que ele suplicante quer abrir hum corte de carne verde, na rua denominada Biquinha, e como a distância do curral que serve de matadouro Público desta cidade fique distante, e fica dificil ao suplicante a condução das rezes que matar para o consumo implora a vossas senhorias para the conceder licença para estabelecer hum curral para a fim pedido, ficando o suplicante obrigado a da parte das rezes, que se matar no dito curral e de cuja graça.

[Despacho] para vossas senhorias o diferimento na forma requerida

Esperar Receber. Mercê. 9

Rodrigues argumentava que o curral utilizado como matadouro municipal era distante e a estrada de difícil acesso, por isso, pedia a permissão para a construção de um curral mais próximo para facilitar a condução do gado. Para isso, solicitava licença para abrir um corte de carne verde na Rua da Biquinha. Propostas como essas eram enviadas à Câmara Municipal, que organizava comissões para a votação de pedidos. Se o parecer fosse favorável, a Câmara determinava os requisitos necessários para o funcionamento do prédio.

\section{As notícias vindas dos jornais: higiene e epidemias}

Os jornais impressos foram um importante meio de comunicação para o periodo. Publicavam notícias da cidade (discussões ocorridas nas seções da Câmara Municipal, anúncio de comerciantes), da província, e algumas que chegavam da Europa. O periódico goiano O Tocantins, era dirigido por Felipe Antônio Cardozo Cruz, publicado cerca de duas vezes por semana e circulou entre 18551857. ${ }^{10}$ No ano em que O Tocantins inicia suas publicações, chega à província uma epidemia que estava presente em algumas cidades do Império e vitimado muitas pessoas. A epidemia cholera morbus estava espalhada por todo o País e o periódico ${ }^{11}$ publicava, em suas edições ensinamentos sobre a higiene pessoal e sanitária para que os populares, a partir dos ensinamentos, melhorassem seus hábitos e não adquirissem o mal. Dentre as práticas publicadas no O Tocantins estava não deixar secar as roupas nos quartos em que habitavam e não lavar a roupa, especialmente "da que tem servido a doentes epidemiados no interior das casas e nem mesmo nos quintais e áreas".12 Além disso, a umidade do ar seria uma causa ativa da epidemia, poderia carregar o ar de impurezas, por isso, estavam atenciosos a todos esses ensinamentos. Moraes (1995) destaca que,

\begin{abstract}
Esse mal, originário da Ásia, causado pelo vibrião colérico, disseminado águas contaminadas, caracterizado por vômitos, evacuações (de 20 a 30 vezes ao dia), fraqueza e abatimento geral era tão constante, que figurava como disenteria nos mapas do Hospital não demandando maiores cuidados por não se ter muito o que fazer, apesar de ser considerado muito doloroso e grave.
\end{abstract}

Podemos concluir que o cholera morbus era contraido pela água e, também, através do alimento. Causava uma grave diarreia, vômitos e desidratação. Vitimou muitas pessoas no periodo, que acabavam indo a óbito por desinformação sobre os procedimentos para com quem contraísse a doença. Entre os anos de 1813-1816, "o cholera era constante" ele constava nos mapas, relação de entrada e saida do Hospital de Caridade São Pedro de Alcântara, como disenteria (DIAS; LEMKE; MORAES, 2018, no prelo).

Além de serem publicadas em jornais, as questões referentes à saúde pública também estiveram presentes nos relatórios de presidentes de província, principalmente no periodo que a província estava em alerta por causa do cholera morbus. O doutor Antônio Augusto Pereira da Cunha, presidente da Província de Goiás, em 1856, em seu relatório apresentado à Assembleia Legislativa Provincial diz que: "Aprovei provisoriamente como lei alguns artigos de

\footnotetext{
9 CIDADE DE GOYAZ. Câmara Municipal de Goiás - requerimento de licença para construir um curral para abater rezes para vender num corte de carne verde. Pedido de Licença, ano 1855. Arquivo Frei Simão Dorvi. Caixa, matadouro municipal - carne verde (1840 a 1899) (1902 a 1871).

10 O TOCANTINS (Goiás). Acervo de documentos da Rede de Estudos de História da Educação de Goiás. Rede de Estudo de História da Educação de Goiás. Disponivel em: http://acervo.fe.ufg.br/index.php/o-tocantins. Acesso em: 10 abr. 2018.

11 Preceitos Geraes de Hygiene. O Tocantins. Jornal Noticioso. Cidade de Goyaz, ano 1855, p. 3 Typographia goyazense1 de dezembro de 1855. IPEHBC.

12 Idem.
} 
posturas que a Câmara da capital organizou a bem da salubridade pública, os quais vos serão presente". ${ }^{13}$ Tais posturas foram aprovadas como medida preventiva, a fim de evitar ou, ao menos, diminuir a força e o impacto do cholera morbus.

"A criação das posturas a partir do século XIX como forma de normalização da sociedade, normatização do espaço urbano e de organização do espaço citadino resultou na disciplina alguns hábitos e na extinção de outros" (SCHMACHTENBERG, 2013). Tomamos, por exemplo, alguns como: "a criação e deposito de porcos, coelhos, galinhas, patos e etc... é expressamente prohibido por uma postura municipal de suma utilidade". ${ }^{14}$

\section{Considerações finais}

Autoridades da província de Goiás no século XIX, inseridas em um contexto de mudança de hábitos, encontram na obrigação de ensinar posturas e práticas de higiene à sociedade, entretanto, para evitar o contágio e o surto de doenças. Gradativamente o Estado realizou intervenções, providenciando decretos, leis e projetos com o propósito de resolver algumas questões do espaço público. Conforme sociedade goiana mudava, observou-se que as primeiras posturas criadas em 7 de fevereiro de 1831, "foram sendo alteradas ao longo do império" (RABELO, 2002, p. 17). Os populares analisavam a situação e solicitavam às autoridades que resolvessem a questão, principalmente, quando a solução do problema não estava prevista nas posturas municipais.

A solicitação da Câmara Municipal à Assembleia provincial de Goiás para que fosse executado o artigo 14 (o artigo 14 estabelecia como deveria ser a venda de carne, a higiene das casas de talho, a qualidade e estabelecia punição para aqueles que o descumprissem) das posturas de 7 de fevereiro de 1831, em 1856, e a publicação das práticas sobre higiene nos jornais desde 1855 (ele ensinava como se prevenir para não adquirir doenças e o que fazer se estivesse doente), indi- cam que as autoridades estavam preocupadas com a higiene e com os açougues. Tal preocupação surgiu porque chegava à Província de Goiás uma epidemia do cholera morbus. Em vista disso, medidas de controle e de vigilância dos açougues foram sancionadas, pois era possivel estabelecer uma possivel relação entre contrair a enfermidade por meio do alimento.

Nesse sentindo conclui-se que a legislação para o comércio da carne em Goiás era rigorosa, primeiro porque haviam sido criados os Códigos de Posturas e, segundo, porque o cólera poderia ser contraído também através de alimentos contaminados. Então, o certo seria acabar com os possiveis meios de contágio do mal. O descumprimento de tais legislações resultaria no pagamento de multa e até a prisão, não deixando também de contribuir para o surgimento de problemas sociais, como por exemplo, surtos de epidemias.

\section{Referências}

CORBIN, Alain. Saberes e Odores: O olfato e imaginário social nos séculos XVIII e XIX. São Paulo: Companhia das Letras, 1987.

DIAS, Thiago Cancellier; LEMKE, Maria; MORAES, Cristina de Cássia P. Fomos aqui acometidos por três flagelos: a varíola, o morbo e a cólera: um ensaio sobre as epidemias nos Guayazes. Goiânia, 2018. No prelo.

GIODARNO, Carolina Celestino. As ações sanitárias na imperial cidade de São Paulo: Mercados e Matadouros. 2006. Dissertação (Mestrado) - Programa de Pós-graduação na aera de arquitetura e Urbanismo do Centro de Educações Ambientais e Tecnologia, PUC. Campinas. 2006. Disponivel em: http://tede.bibliotecadigital. puc-campinas.edu.br:8080/jspui/handle/tede/42. Acesso em: 25 mar. 2018.

MORAES, Cristina de Cassia Pereira. As estratégias de purificação dos espaços na capital da provincia de Goiás (18531843). 1995. Dissertação (Mestrado) - UFG, Goiânia, 1995.

NOGUEIRA, Luiz Gabriel de Souza; SENA, Divino Marcos de. "Gado para o consumo": Comércio de carne verde e açougueiros em Corumbá 1870-1888 (Província de Mato Grosso)."Cattle for consumption": fresh meat trade and butchers in Corumbá 1870-1888 (Mato Grosso Province). Revista territórios \& fronteiras. Cuiabá, v. 6, n. 2. p.1 42-165, jul./dez. 2013. Disponivel em: https://dialnet. unirioja.es/servlet/articulo? codigo $=4807287$. Acesso em: 15 jan. 2018. https://doi.org/10.22228/rt-f.v6i2.199

13 GOIÁS (Estado). Assembléia Legislativa Provincial de Goyaz. Relatório de Presidente de Provincia. Relatório apresentado à Assembleia Legislativa Provincial de Goyaz na sessão ordinária do ano1856 pelo Exmo. Presidente da provincia Dr. Antônio Pereira da Cunha Memórias Goianas $n^{\circ}$ 7. Relatórios políticos, administrativos, econômicos, sociais, etc, dos governos da província de Goiás (1856-1859). Goiânia: UCG, 1997.

14 Idem. 
RABELO, Danilo. Os excessos do corpo: a normalização dos comportamentos na Cidade de Goiás (1822-1889). 1997. Dissertação (mestrado) - UFG, Goiânia, 1997. Disponivel em: https://pos.historia.ufg.br/n/20854-ano-1997-dissertacoes Acessado em: 07 ago. 2017.

RABELO, Danilo. As representações juridico-policiais sobre a prostituição na Cidade de Goiás. Em tempos de História, Brasília, DF, n. 6, p. 1-29, 2002. Disponivel em: https://periodicos.unb.br/index.php/emtempos/ article/view/20173. Acesso em: 20 nov. 2017.

ROSEN, George. Uma história da saúde pública. São Paulo: Hucitec. 1994.

SCHMACHTENBERG, Ricardo. Código de postura e regulamentos: Vigiar, controlar e punir. Vestigios do passado a história e suas fontes. Porto Alegre: ANPUH-RS, 2008. p 1-13. Disponivel em: http://eeh2008.anpuh-rs. org.br/resources/content/anais/1209158027_ARQUIVO_CODIGOSDEPOSTURAS.pdf. Acesso em: 10 out. 2017.

\section{Manuscritas}

\section{Arquivo Frei Simão Dorvi- AFSD}

Caixa, Matadouro municipal - carne verde (1840 a 1899) (1902 a 1871). Câmara Municipal de Goiás- requerimento de licença para construir um curral para abater rezes para vender num corte de carne verde. Ano 1855

\section{Arquivo Histórico do Estado de Goiás- AHEG}

Caixa 111, Código de Postura- Assembleia Legislativa-1856

Instituto de Pesquisas e Estudos Históricos do Brasil Central- IPEHBC

Caixa Legislação- Goiás, Relatório do Presidente da Província de Goyaz, DrAntonio Gomes Pereira Junior, apresentado à Assembleia Legislativa Provincial de Goyaz, passando a administração da província para o Dr Theodoro Rodrigues de Moraes, no dia 22 de fevereiro de 1883. Goyaz Typographia Provincial.1883.

O Tocantins. Goyaz. Typographia Goyazense 1855-1857.

\section{Impressas}

Memórias Goianas $n^{\circ} 7$. Relatórios políticos, administrativos, econômicos, sociais, etc, dos governos da provincia de Goiás (1856-1859). Goiânia: UCG, 1997.

\section{Naelma Mendes do Nascimento}

Historiadora, graduada em História pela Universidade Federal de Goiás (UFG), em Goiânia, GO, Brasil, e graduanda em Direito pela Universidade Federal de Uberlândia (UFU), em Uberlândia, MG, Brasil. Pesquisadora, na Universidade Federal de Goiás (UFG), com estudos voltados para História do Brasil e História Regional do Brasil.

\section{Endereço para correspondência}

Naelma Mendes do Nascimento

Universidade Federal de Goiás (UFG)

Faculdade de História

Av. Esperança, s/n.

Chácaras de Recreio Samambaia, 74690900

Goiânia, GO, Brasil 